\title{
Using Cognitive Load Theory to interpret student difficulties with a Problem Based Learning approach to Engineering Education: A Case Study.
}

\author{
Michael Peters* \\ Aston University, School of Engineering and Applied Science, Aston Triangle, Birmingham, \\ B4 7ET. \\ *Email: m.peters@aston.ac.uk
}

\begin{abstract}
This paper reports on an investigation with first year undergraduate Product Design and Management students within a School of Engineering and Applied Science. The students at the time of this investigation had studied fundamental engineering science and mathematics for one semester. The students were given an open ended, ill formed problem which involved designing a simple bridge to cross a river. They were given a talk on problem solving and given a rubric to follow, if they chose to do so. They were not given any formulae or procedures needed in order to resolve the problem. In theory, they possessed the knowledge to ask the right questions in order to make assumptions but, in practice, it turned out they were unable to link their a priori knowledge to resolve this problem. They were able to solve simple beam problems when given closed questions. The results show they were unable to visualise a simple bridge as an augmented beam problem and ask pertinent questions and hence formulate appropriate assumptions in order to offer resolutions.
\end{abstract}

\section{Introduction}

The majority of learners come to university with predominantly procedural knowledge, they know how to apply a procedure to a set of variables and constants and obtain a result but with little understanding of what the result implies or means. They do not seem to possess the conceptual knowledge necessary to be able to make assumptions or an informed judgement as to how sensible their result is or indeed be able to interpret the outcome. This is not surprising since in the UK education system, schools are judged on their academic performance by a regime of league tables. The learners are at level three of the English NQF (National Qualifications Framework) immediately prior to entering university and are mainly assessed via formal examinations. This form of assessment predominantly measures procedural knowledge and is used as the primary indicator of students achievement, since in the consultation on the new A level regulatory requirements, OFQUAL (Office of Qualifications and Examinations Regulation) deemed assessment via coursework as unreliable (OFQUAL, 2013).

One of the major challenges facing university engineering schools is to enhance this procedural knowledge into conceptual knowledge and to develop the skills required by a contemporary engineer. The vast majority, if not all, undergraduate engineering 
programmes feature a project, group or individual, as a final year module. In this restricted form of PBL (Problem Based Learning), learners are in some cases, given a teacher-selected problem which is based upon the learners' a priori knowledge and skills (Heitman, 1996).

Although this approach embraces the notion of problem solving learning, it represents a small fraction of the curriculum, is time restricted and contrived, and cannot be accurately described as PBL. In order to fully develop the knowledge and skills required by a professional engineer, a more holistic and curriculum wide approach is necessary (Zhou, 2012). PBL is seen as a solution to equip graduate engineers with the necessary skills and knowledge to make them 'industry ready'.

In recent times a number of institutions have developed programmes of study, where PBL is used as the vehicle to enhance student learning (for a number of case studies see (Du, et al., 2009a). The purpose of this paper is to report on a preliminary investigation involving problem based learning with first year undergraduate students enrolled on a design programme within a school of Engineering and Applied Science.

The paper begins with a discussion of the theoretical aspects of Problem Based Learning (PBL), including a discussion of the various models which can and have been implemented in Higher Education (HE). ). Following a discussion of how knowledge and skills are acquired, the next section briefly discusses aspects of learner identity and in particular the notion of mathematical resilience (Johnston-Wilder \& Lee, 2010). The methodology used in this investigation is discussed along with the participants. Finally, the paper discusses the results of the investigation, drawing on the literature and conclusions from this study to make recommendations on future programme design.

\section{Problem-Based Learning}

PBL is firmly rooted in the tradition of Vygotsian constructivism (Vygotsky, 1978), where learning takes place in a social context with the learners constructing knowledge through interaction with others. One of the main motivating factors for introducing PBL into engineering curricula is the need for the contemporary engineer to be, not only a subject specialist, but also to lead a team, work as part of a team and importantly be able to communicate effectively (Sheppard, 2008). The notion of the engineer being a 'back room boffin', has long gone. Companies say they require multi-skilled graduates who have, amongst other attributes, the potential to manage projects and solve problems (Zhou, 2012).

There is an assumption within HE that students are capable of problem solving based on their educational experience prior to enrolment. Although the UK technical specifications for the numerous level three qualifications (for example Edexcel (2008, p. 146)) include problem solving as a key skill, it is evident that few students are capable of resolving complex, openended and ill-formed problems. There are many reasons for this which include how teachers conceive their role, the pressure on teachers to ensure their students perform well in summative examinations, and the level of content teachers' are expected to deliver in a limited amount of time. In addition to this, the interpretation of what constitutes a 'problem' is not clearly defined. There seems to be a disconnection between what schools, colleges, 
universities and industry define to be a problem. At one end of the spectrum problems tend to be well-formed with known solutions, and at the other problems tend to be open-ended and ill-formed (particularly in engineering practice) (Sheppard, 2008).

The phrase Problem Based Learning does not define a unique educational method; it has been used to encapsulate the notion of a 'system' which includes both a curriculum and a process of learning (Donnelly \& Fitzmaurice, 2005). It has also been described as an educational philosophy which covers a wide range of practices (Du, et al., 2009b).

Graaff and Kolmos (1993) analysed the various problem-based learning models and identified common learning principles that can be captured in three themes; learning, contents and social. Firstly, they describe the cognitive learning approach to be where learning is organised around problems and carried out in projects. The problem is the initial condition which informs the learning process, contextualises the learning and takes into account the learners' a priori knowledge and skills. By using a project as the basis for learning, a time frame is also implied.

Secondly, the contents approach is particularly focussed on interdisciplinary learning and the possibility of crossing traditional subject boundaries and methods. The problem is designed to support the relationship between theory and practice by employing the theory as the basis for the analysis of the problem and the methods used to solve it. Finally, the social approach is in essence a team-based learning methodology. Learning takes place through dialogue and communication between the team members. Additional skills fostered by this approach are the learning to share knowledge and the organisation of collaborative knowledge. These generalised learning principles provide an institutional level framework in which specific models can be implemented.

Savin-Baden (2000, p126) in the outcome from her analysis of staff and student experiences, proposed five models of problem based learning. She suggested models for epistemological competence (model 1), professional action (model 2), interdisciplinary understanding (model 3), transdisciplinary learning (model 4) and critical contestability (model 5). Each of the models was broken down into the type of knowledge to be learned, what learning should take place, the problem scenario, the role of the student, the role of the facilitator and finally the form of assessment.

Although by suggesting different models implies that each model is a discrete entity, it is important to realise that the models do overlap. According to Savin-Baden (2005) the ideal model is model five which in theory promotes multiple models of action, knowledge, reasoning and reflection. It also affords opportunities for students to challenge, evaluate and interrogate. However, she does acknowledge that this model may be a utopian dream in the current educational climate where accountability, professional and academic competence are the driving factors.

An important aspect Savin-Baden (2000) did highlight was the notion of learner identity. She makes the point that PBL can challenge the learners' conception of what counts as knowledge and what it means to be a learner. Learners' often view knowledge as fixed and as Eraut 
(1994) suggested, when faced with the idea that knowledge borders are not fixed, there is a danger that learners' will accept propositional knowledge provided by tutors in an unquestioning and uncritical way.

In order for learners to be effective problem solvers they must be able to make sensible assumptions, be comfortable with the notion of resolutions and be prepared to adopt trial and improvement techniques. In addition to these skills the students must also be knowledgeable, confident and competent within the subject disciplines.

\section{Research Question}

This investigation resulted from conversations with a particular group of students concerning how they coped with resolving the engineering problems set for them in engineering classes where a problem based learning approach was used to facilitate learning. This investigation was implemented in order to attempt to find out if cognitive theories are able to provide an explanation as to why these students found a problem based learning approach challenging.

\section{The Participants}

The 12 students who participated in this investigation were first year undergraduate product design and management students. A typical qualification profile was: 'A' levels in Product Design, Humanities subjects and rarely Mathematics or Physics. Prior to the investigation the students had studied Mathematics and Engineering Science for one semester. These lessons covered such topics as resolutions of forces, beams, algebra and solving equations.

This group of students also participated in problem based learning classes alongside other engineering students who had achieved ' $A$ ' level mathematics or equivalent prior to studying engineering at university.

\section{Research Methodology}

At the outset of this investigation, the decision was made to adopt an ethnographic approach and use direct observation. This would provide the basis on which to inform a grounded theory on the behaviour of the participants to solving an open ended, ill-formed problem. The ethnographic approach was originally developed in the field of anthropology where researchers would immerse themselves and become participants within the culture of a particular ethnic group. In more recent times, the definition of a culture has been broadened to include virtually any group or organisation. In this particular investigation it was important not to become an active participant, rather a direct observer of the interactions between the group members. In this way more meaningful conclusions could be drawn on the approaches to problem solving adopted by the learners.

\section{The Investigation}

The participants were given an open-ended, ill-formed problem which focussed on them designing a simple bridge to ford a river. The only information they were given concerned the width of the river and the height of its banks. They were also given a talk about using a problem solving rubric. They were not instructed on any formulae they would need or how 
to go about resolving the problem. The participants were asked to work in pairs and the investigation ran for three 3 hour sessions.

\subsection{The Task}

The students were given a worksheet which detailed the following problem: An outward bound company has set up a new campsite for young people in the Brecon Beacons National Park. There is a river running through the site which effectively separates the main camp site from the cook house. The river is $3 \mathrm{~m}$ wide and the mean height of the river bank is $1 \mathrm{~m}$. During periods of heavy rain the river can overflow the banks. The management team have decided that they need to build a safe, simple bridge at minimal cost which would enable the young people to access the cook house all year round.

The students were instructed to investigate and report back to the management team how they would resolve this issue. They were required to explore resolutions which incorporate different designs and recommend a solution which was cost effective and fit for purpose.

\subsection{Problem solving rubric}

In order to assist them in the process of problem solving they were shown the following rubric:

Exploring the problem:

1. What information is given by the problem?

2. What is the problem asking me?

3. Is there additional information I need to get started?

Resolving the problem

1. Have I resolved a similar problem before?

2. Do I know the mathematics to solve this problem?

3. What assumptions, if any, do I have to make?

4. Can the problem be broken down into smaller, more manageable problems?

5. Can the problem be looked at from a different perspective?

Reviewing my resolution

1. Is my resolution acceptable?

2. What have I learned from the resolution?

3. Could I use this resolution to resolve other problems?

\subsection{Session 1.}

At the start of this session the investigation was explained. The explanation included what was expected of them, the investigators role and that they would not be assessed on their performance. Consent was obtained from the students who were willing to participate in the investigation. They were also told they could self-select whom they wished to work with. 
The students were given the task which they were expected to attempt followed by a discussion of the problem. In this discussion it was also made clear that, since it was an open-ended, ill-formed problem they were free to tackle the problem in any way they deemed as suitable and that trail and improvement techniques were an acceptable part of the problem solving process. The process of problem solving was also discussed and a rubric given to them. They were informed that this problem solving rubric should be used as a guide and they were free to use whatever procedure they were familiar with.

The students spent the first part of the session sketching their conceptions of bridges. These sketches included such designs as suspension bridges and swing bridges. The investigator noted that none of the groups discussed the engineering science or the mathematics they would need to use to ensure their design was fit for purpose. Once they were satisfied with their sketches, they started to think about the analytical techniques they would need to use. Since the investigator was purely observing, they were left to discuss the various analytical techniques without intervention. It was evident that none of the groups could identify a starting point for their analysis. After some time, the investigator decided to intervene since the students were being to get frustrated and go off task. A class discussion ensued where they were guided towards thinking about the simplest form of a bridge and the forces they would need to analyse.

It was also evident at this point that they were not competent in the problem solving process even though they had a rubric which they could have used as a guide. They were not comfortable with making assumptions and constantly asked the investigator to tell them where they should start. During the discussion concerning the technical aspects of the problem, the notion of making assumptions as a starting point was also discussed.

Once the discussion was over the students were once again left to tackle the problem. The investigator observed that although they should have known such scientific laws as Newton's Third Law, they could only partially recall it. They knew that there would be a downwards force but failed to take into account the concomitant reactionary force. The investigator decided not to intervene and asked them to remind themselves of the fundamental laws of forces in preparation for the next session.

\subsection{Session 2.}

In the second session many of the students had adopted, as a starting point, a wooden beam laid between the two banks. They proceeded to identify and signify the forces acting upon their bridge. Although they had correctly identified the forces and where they would act, they were unable to proceed since they had not considered factors which would influence the loading of their bridge. At this stage, they needed to make assumptions about the loading of the bridge ie. the number of people who would be on the bridge at any one time which would influence the dimensions of the bridge and hence the weight of the bridge itself. They should also have considered the amount of flexion that was permissible if their bridge was to be safe and comfortable to traverse. 
As in the previous session, the students became disengaged with the task since they had reached a point in the problem which they could not deal with. The investigator decided to intervene and lead a discussion on aspects of designing a simple bridge. This discussion included what type of loading model should be considered ie. should a point or a distributed load model be used. A table of mathematical formulae was shown to them. It was clear that they were overwhelmed with the mathematical symbolism and could not interpret the formulae and therefore make an informed choice of which loading model to use.

\subsection{Final session.}

The groups who had correctly identified the forces they needed to analyse still were unable to implement the assumptions they had made concerning the loading and dimensions of the bridge. As in previous sessions, they were expecting the investigator to intervene and tell them which formulae to use and how to apply it. Again, once it was clear the investigator was not going to intervene, they quickly became disengaged with the task.

In order for the learning experience to be a positive one, the investigator implemented a class discussion where finally a simple bridge was designed. The investigation was reviewed and the comments the students made concerning their behaviour in attempting to resolve the task noted.

\section{Discussion of results.}

It was evident from the start of the investigation that the students found it extremely difficult to form assumptions and to implement a problem solving strategy. In some respects, this is not surprising since they were used to being 'taught' and not expected to take responsibility for their own learning. This aligns with Savin-Badin’s (2007) discussion of learner identities in which she observed that many learners' expectations of learning involved the tutor to be the dispenser of knowledge. She goes on to say, how many learners' struggle with the notion of problem solving, learning through dialogue with peers and the value of their prior learning experiences. Also, the students in this study disengaged with the process when they faced a problem which they considered insurmountable. One explanation for this could be they were not 'mathematically resilient' (Johnston-Wilder \& Lee, 2010). Johnston-Wilder (2010) discussed how students do not seem to be able to persevere with a problem until a reasonable resolution can be found. In the case of this study, the students had the opportunity between sessions to review their existing knowledge and skills and to rectify any deficits. The process of learning by problem solving constantly entails following 'red-herrings', going down 'blind alleys' and meeting obstacles that have to be overcome. In this respect, the process of problem solving mimics how mathematics developed over centuries. Another explanation for the students disengaging when faced with challenging problems is they could not relate the problem to a known simple mechanical model and use this as a starting point.

They had conceptions as to what a bridge looked like, but failed to consider the fundamental purpose of a bridge and hence look at a basic structure that would afford this utility. In 
addition to their inability to simplify the system, it was evident that they did not link the theoretical aspects of their programme of study with its implementation, although they had previously demonstrated in the theory classes their ability to resolve forces, manipulate algebraic expressions and generally cope with solving equations. In some sense, this highlights the difference between 'straight' mathematics and engineering mathematics. The engineer uses mathematics to describe and investigate a physical system (Redish \& Smith, 2008) and, as stated previously, in many cases students do not intuitively make these connections and therefore need guidance to make them.

In order to be competent problem solvers, learners require schemata linking a priori mathematical knowledge and skills with physical systems. The participants in this study demonstrated they had developed mathematics schemata in algebraic manipulation, solving equations and solving closed, well-formed problems. Similarly, in the engineering science aspects of their programme of study, they were able to resolve forces, calculate moments and apply mathematics formulae to a given problem. Cognitive Load Theory (Sweller, 2010) could be used to give an insight into the underlying cognitive processes. The students were expected to use elements of the 'randomness as genesis' principle in that they were not given a starting point to resolve the problem and therefore had to form assumptions and adopt a 'trail and improvement' approach. In order to make the initial assumptions they would have to have a clear notion of the affordances a bridge offered ie. a means of crossing the river in a safe, comfortable manner. The next step on from this would be to take the concrete situation and produce a mathematical model which could account for their assumptions and yet be simple enough to be amenable to analysis. Although this appears at first sight a relatively straight forward process, the step from going from a real situation to a 'situation model' (Blum \& Leiss, 2005) can be problematic in that the students need to know precisely what they are trying to resolve. In terms of CLT, they would rely upon a priori knowledge and the schemata they have constructed from similar problems in order to make sense of the situation and therefore produce the situation model. It is at this point the students in this student had great difficulty. As was observed in the first session, the students were able to sketch a bridge but were unable to use the affordance of a bridge to construct the situation model and hence construct a mathematical model. This situation led to them becoming frustrated and going off-task with the result an unplanned investigator intervention had to occur in order to get them back on-task. The final stages of the modelling cycle ie. interpretation of their results and forming a judgement as to their validity, seemed an irrelevant task. In other words, they believed once they had completed their calculations the problem was resolved.

\section{Conclusions}

Since its emergence at McMasters University (Woods, 1994), PBL (Problem Based Learning) has had mixed responses. Many advocate its benefits in terms of education, yet others report of little benefit to learners (Van Barneveld \& Strobel, 2009). In fact, there is very little evidence in general for 'constructivist' based approaches, to support the notion of an increase in student knowledge (Kirscher, et al., 2006). 
Alongside the technical aspects of problem solving, learners also require personal attributes such as mathematical resilience, confidence in their a priori knowledge and skills, a positive learner identity and a realisation that problem solving is a legitimate form of learning. It is 'unsafe' to assume learners will have developed these attributes during their pre-university studies, even though Awarding Organisations state problem solving as one of the key skills that should be developed. Unless these aspects are addressed, then learners will continue to be strategic in their learning since they are not equipped to become 'deep learners' as defined by Biggs and Tang (2007).

Although, in principle like many learning philosophies, Problem Based Learning does meet the needs of contemporary engineers, there needs to be a clear and well-articulated reason for introducing it into the curriculum and its implementation requires careful and detailed planning (Kolmos, et al., 2009). As Kolmos et al (2009) pointed out, for PBL to be effective, learning objectives have to be aligned with the correct types of problems, learning processes, facilitator roles and assessment.

This study demonstrated that to expect learners to be proficient problem solvers without a graduated initiation to problem based learning, they become overwhelmed and end up disengaging with the process. CLT, therefore offers an explanation as to why this situation can arise. If learners do not have the fundamental mathematics knowledge and skills to support the problem solving process, they will find it extremely challenging and in all likelihood, not fully engage and consequently derive little benefit from the learning environment. In order to be competent problem solvers, the learners also need to have a solid foundation of resilient schemata encompassing many aspects of mathematics and engineering science. Alongside this, they also need to be encouraged to develop problem solving skills such as forming and working with assumptions, interpreting results and making judgements as to the validity of their results. These problem solving skills are essential if students are expected to develop mathematical models of 'real world' problems. The students in this study had great difficulty in taking a real situation, developing a situation model leading to real model. The process of developing an abstract mathematical model from the real model was therefore impossible for them without an investigator intervention. Once they had constructed a mathematical model they were able, with some assistance, to perform the necessary calculations. At this point they believed the task was resolved.

To summarise: in order for students to become competent engineers they need to have a robust knowledge and skills base, be introduced to problem solving by a series of graduated problems, be able to develop a realistic mathematical model and be able to make judgements as to the validity of their results. 


\section{Bibliography}

Biggs, J. a. T. C., 2007. Teaching for Quality Learning at University. 3rd ed. Buckingham: SRHE and Open University Press.

Blum, W. \& Leiss, D., 2005. 'Filling Up' - The problem of independence-preserving teacher interventions in lessons with demanding modelling tasks. s.l., s.n., pp. 1623-1633.

Donnelly, R. \& Fitzmaurice, M., 2005. Collaborative Project-Based Learning and Problem Based Learning in Higher Education: A consideration of Tutor and Studen roles in learner-focussed strategies.. In: G. O'Neill, S. Moore \& B. McMullin, eds. Emerging Issues in the Pratice of UNiversity Learning and Teaching. Dublin: s.n.

Du, X., de Graaff, E. \& Kolmos, A., 2009a. Research on PBL practice in engineering education. Rotterdam: Sense.

Du, X., de Graaff, E. \& Kolmos, A., 2009b. PBL-Diversity in research questions and methodologies. In: X. Du, E. de Graff \& A. Kolmos, eds. Research on PBL practice in engineering education. Rotterdam: Sense, pp. 1-8.

Edexcel, 2008. Edexcel GCE Maths e-spec. [Online] Available at: http://www1.edexcel.org.uk/espec08/maths/wrapper.html [Accessed 12 August 2014].

Eraut, M., 1994. Developing professional knowledge and competence. London: The Falmer Press. Graaff, E. d. \& Kolmos, A., 1993. Characteristics of Problem-based Learning.. International Journal of Engineering EDucation, 19(5), pp. 657-662.

Heitman, G., 1996. Project-oriented study and projects-organized currilcula:A brief review of intentions and solutions. European Journal of Engineering Education, 21(2), pp. 121-131.

Johnston-Wilder, S. \& Lee, C., 2010. Mathematical resilience. Mathematics Teaching, Volume 218, pp. 38-41.

Kirscher, P., Sweller, J. \& Clark, R., 2006. Why minimal guidance during instruction does not work: An analysis of the failure of constructivist, discovery, problem-based, experiential and inquiry-based teaching. Educational Psychologist, Volume 41, pp. 75-86.

Kolmos, A., De Graff, E. \& Xiangyun, D., 2009. Diversity of PBL - PBL learning principles and models. In: D. Xiangyun, E. De Graff \& A. Kolmos, eds. Research on PBL Pratice in Engineering Education. Rotterdam: Sense.

OFQUAL, 2013. Consultation on New A level Regulatory Requirements, Coventry: Office of Qualifications and Examinations Regulation.

Savin-Baden, M., 2000. Problem Based Learning in Higher Education: Untold Stories. Buckingham: SRHE and OUP. 
Savin-Baden, M., 2007. Challenging Models and Perspectives of Problem-Based Learning.. In: E. Graff \& A. Kolmos, eds. Management of Change:Implementationof Problem-Based and Project-Based Learning in Engineering. Rotterdam: Sense Publishers, pp. 9-29.

Sheppard, S. M. K. C. A. S. W., 2008. Educating engineers, designing for the future of the field. San Francisco: Jossey-Bass.

Sweller, J., 2010. Cognitive Load Theory: Recent theoretical advances. In: Cognitive Load Theory. New York: Cambridge University Press, pp. 29 -47.

Van Barneveld, A. \& Strobel, J., 2009. Problem Based Learning: effectiveness, drivers, and implementation challenges. In: X. Du, E. de Graff \& A. Kolmos, eds. Research on PBL in Engineering Education. Rotterdam, The netherlands: Sense Publishers, pp. 35-44.

Vygotsky, L., 1978. Mind in Society: The development of higher psycholological processes. Cambridge, MA: Harvard University Press.

Woods, D., 1994. How to gain most from Problem Based Learning. Hamilton, Ontario: McMaster University press.

Zhou, C., 2012. Fostering creative engineers: a key to face the complexity of engineering practice. European Journal of Engineering Education, 37(4), pp. 343-353. 